\title{
The Psychological Adjustment of Children with Asthma: Study of Associated Variables
}

\author{
Lígia Lima ${ }^{1}$, Marina Prista Guerra ${ }^{2}$, and Marina Serra de Lemos ${ }^{2}$ \\ ${ }^{1}$ Escola Superior de Enfermagem do Porto (Portugal) \\ ${ }^{2}$ Universidade do Porto (Portugal)
}

\begin{abstract}
As part of a larger research project aimed to understand the impact of asthma in the psychological adjustment of children, this study focuses in the identification of factors associated with this process. The sample of this study consisted of 89 children, aged 8 to 12 with physician diagnosed asthma. To assess children's adjustment, the Portuguese versions of the following instruments were used: School-age Temperament Inventory (McClowry, 1995) Schoolagers Coping Strategies Inventory (Ryan-Wenger, 1990); Pediatric Quality of Life Inventory PedsQL (Varni, Seid \& Kurtin, 2001); The Self-perception Profile for Children (Harter, 1985), Child Behavior Checklist (Achenbach,1991); Social Skills Rating System (Gresham \& Elliot, 1990). The results revealed that negative reactivity predicts the level of anxiety/depression, task persistence and perceived coping efficacy predicts social skills and that self-esteem is a significant predictor of the perceived quality of life. A significant proportion of shared variance was also found what seems to confirm the existence of multi-determination in the process of adjustment. The main conclusion is that two dimensions of temperament (negative reactivity and task persistence), as well as perceived coping efficacy and self-esteem, play a significant role in influencing the psychological adjustment of children with asthma.
\end{abstract}

Keywords: asthma, psychological adjustment, correlates.

Como parte de un proyecto de investigación más extenso cuyo objetivo es comprender el impacto del Asma en el ajuste psicológico de los niños, este estudio se centra en la identificación de los factores asociados a este proceso. La muestra de este estudio incluyó a 89 niños con edades comprendidas entre los 8 y 12 años y con diagnóstico médico de asma. Para medir el ajuste de los niños se utilizaron versiones en portugués de los siguientes instrumentos: School-age Temperament Inventory (McClowry, 1995) Schoolagers Coping Strategies Inventory (Ryan-Wenger, 1990) ; Pediatric Quality of Life Inventory - PedsQL (Varni, Seid \& Kurtin, 2001; The Self-perception Profile for Children (Harter, 1985), Child Behavior Checklist (Achenbach,1991); Social Skills Rating System (Gresham \& Elliot, 1990). Los resultados revelaron que la reactividad negativa predice el nivel de ansiedad/depresión, la persistencia de tarea y la eficacia de afrontamiento percibida predicen habilidades sociales y que la autoestima es un predictor significativo de la calidad de vida percibida. Se encontró también una proporción significativa de la varianza compartida lo que confirma la existencia de multi determinación en el proceso de ajuste. La conclusión principal es que dos dimensiones de temperamento (reactividad negativa y persistencia en la tarea), así como la eficacia de enfrentamiento percibida y la autoestima, juegan un papel significativo en el ajuste psicológico de los niños con asma. Palabras clave: asma, ajuste psicológico, correlatos.

Correspondence concerning this article should be addressed to Lígia Lima. Escola Superior de Enfermagem do Porto. Rua Dr. António Bernardino de Almeida. 4200-072 Porto. (Portugal). E-mail: ligia@esenf.pt 
Asthma is the most common chronic disease in childhood, and has a well-documented psychosocial impact, in the child as well as in the family and in others groups to which the child belongs (Bacharier, Boner, Carlsen, Eigenmann, Frischer et al. 2008; World Health Organization, 2000). Despite recent research suggesting that most children with asthma and their families succeed in adapting to this illness without great difficulty (Barros, 1999), there is also evidence that asthma can cause stress and, as such, presents nonnormative challenges that, if not properly overcome, may cause psychological maladjustment (Creer \& Bender, 1995; McQuaid, Kopel \& Nassau, 2001; McQuaid \& Walders, 2003; Thompson \& Gustafson, 1996).

A review of the literature reveals that there are several variables involved in the process of adaptation in children with chronic illness, in general, and asthma in particular. These variables comprise either the expression of the implications of living with diseases of this type at this age, or factors that may aggravate or mitigate the effects of living with this type of pathology. This study concentrated on variables of the individual child, of the child's family, and of the illness, believing that these would be the most determining factors.

For variables related to the child, temperament is one of those that was highlighted in this study as being associated with the child's development and functionality (Rothbart \& Bates, 1998), as well as with the child's physical health (Carey, 2004; Carranza \& Salinas, 2003;) and adaptation to the school environment (Guerin, Gottfried, Oliver \& Thomas, 1994 cited in Rothbart \& Bates, 1998).

Self-esteem is one of the variables most often cited as reflecting the impact of the experience of chronic illness, and it is believed that the physical and social limitations imposed by the characteristics of a chronic illness eventually have an adverse affect on the subjective assessment of self-worth (Thompson \& Gustafson, 1996). There are also authors, who consider the importance of studying self-esteem in children with chronic illness, believing that it may act as protective factor or rather that children who begin with healthy self-esteem are less likely suffer as much from the disease and to adapt to it more easily (Barros, 1999). The variables that assess the type and intensity of stressors in general, and those associated with the disease, as well as the strategies that children and their families use to deal with them (Wallander \& Varni, 1998) are valued by the psychology of child health, especially in the more recent models of stress and coping. It was taken into consideration that children with asthma are, above all, children just like other children, sharing with them the fact that their development is affected by a whole variety of conditions, such as the experience of situations involving the loss of significant persons in the child's life (e.g. parental divorce) or that pose a threat to their sense of security (e.g. change of residence or school).
The experience of life events of this nature increases the child's difficulties in adapting to asthma, since one or more sources of stress are, thus, added to the stress caused by the disease itself. The stress caused to the family system by asthma was also evaluated in this study, by type and amount of changes or interference caused by the presence of asthma in the family's functioning, a variable that Thompson and colleagues (1994) also favored, since they considered it crucial in the child's process of adaptation to the chronic illness.

The literature argues that there is an association between the coping process and the results of efforts to adapt to the illness (Ryan-Wenger, 1996). Children that possess an ample repertoire of coping strategies are frequently resilient to situations involving chronic illness (Compas, Worsham \& Ey, 1992 cited in Barros, 1999; Ryan-Wenger, Sharrer \& Wynd, 2000). The type of strategies a child prefers to use is also a determining factor in their adjustment to this type of pathology, there being evidence that avoidance strategies are generally associated with an increased risk of psychological maladjustment (Thompson \& Gustafson, 1996).

Information was gathered regarding the constitution of the household in which the child lives, among the variables related to family, as non-intact nuclear family structure represents a risk factor for emotional adjustment in children with chronic illness (Brown, Wiener, Kupst, Brennan, Behrman et al. 2008). The mother's mental health is another factor that has been consistently identified as being associated with psychological adaptation in children in general (Pauli Pot, Darui \& Beckman, 1999), as well as children with asthma (Kaugars, Klinnert \& Bender, 2004). Therefore, we chose the mother's humor as a variable to be assessed, since it will necessarily affect the mother's availability to care for and help the child in their efforts to adapt to asthma.

The quality of the psychological adjustment of children with asthma was conceived in a multidimensional manner, and was evaluated via three distinct indicators. The first indicator was the presence of symptoms of anxiety or depression, since the literature argues that such symptoms are frequently present in children with chronic illnesses in general (Barros, 1999), and particularly in those with asthma (McQuaid et al., 2001). Adaptation was also evaluated in terms of competence, or rather, in terms of successful and appropriate performance for the child's development level, focusing on the academic environment, more specifically in terms of the child's social skills and academic competence. School is an extremely important developmental context for children in the age group under study (Masten, Morison, Pellegrini \& Tellegen, 1992), and, as such, adaptation to school is an important developmental milestone for the identification of behavioral problems (Sroufe \& Rutter, 1984 cited in Hérnandez, 1995). 
Finally, adaptation was also evaluated through the generic quality of life perceived by the children themselves. Highly valued by research in Health Psychology, namely on the study of psychological adaptation to asthma, quality of life has been identified as a variable that expresses the degree of success in the management of the disease. (Mishoe, Baker, Poole, Harrel, Arant et al, 1998; Vinson, 2002).

The goals of this study were:

1. To analyze relationships between variables that the theory generally holds as being involved in the adaptation of children with asthma, in particular:

1. To analyze the relationship between anxiety/ depression, social skills and quality of life in children with asthma and the child's characteristics, specifically, their temperament, intelligence, global self-esteem, coping strategies, and quantity of potentially stressful situations experienced in the year prior to the study.

2. To analyze the relationship between anxiety/ depression, social skills and quality of life of children with asthma and characteristics of the child's family, such as the type of household, the mother's humor and perception regarding the interference and changes caused by asthma.

3. To analyze the relationship between anxiety/ depression, social skills and quality of life in children with asthma and the degree of severity of the asthma.

2. To analyze the role of temperament, self-esteem, mother's humor, coping and stress indicators on indicators of adaptation: (1) anxiety/depression (2) social skills (3) generic quality of life of the child.

\section{Method}

\section{Participants}

The sample for this study was comprised of 89 children attending pediatric immuno-allergy consultations in the Central Hospital and family health care in the Porto District health center, with intermittent, light persistent or moderate persistent asthma. The sample was of the sequential and convenience type. Data was collected over a period of approximately 10 months, and covered nearly all of the children to be monitored in the respective services over this period of time. The sample size $(N=89)$ was determined when the cases that met the inclusion criteria were depleted: (a) age between 8 and 12 (b) intermittent, mild or moderate asthma diagnosed during the past year (c) absence of any other type of chronic disease. The classification of the type of asthma was conducted in accordance with the diagnosis made during the consultation that preceded the interview and following the Global Initiative for Asthma [G.I.N.A] criteria (1995). The decision to eliminate cases of severe persistent asthma was linked to the fact that these situations are more susceptible to psychopathology, and, in the opinion of doctors, are sufficiently distinct from cases of the remaining degrees of severity in terms of the frequency and severity of symptoms, interference of symptoms in the child's functioning, or the type of medication administered. We intended, thus, using the chosen criteria, to find a sample that was relatively homogeneous in clinical terms.

Children participating in the sample were between 8 and 12 years of age, with an average age of 9.71 years. Of these $58(65.2 \%)$ were male and the remaining 31 (34.8\%) were female. Most children were accompanied by their mothers $(86.5 \%)$ at the time of consultation and the interview, while the rest were accompanied by the father $(4.5 \%)$, the grandmother $(7.8 \%)$, or both parents (father and mother) (1.1\%).

\section{Instruments}

Various instruments were used in this study, in addition to a questionnaire created specifically for this study, which was filled out by the child's principal caregiver in order to obtain the following information: individual identification and socio-demographics for the child, including age, gender, school year, parents' occupational and academic background, household type (intact or not); stress situations experienced by the child over the previous year (1 item); changes and interference in family life caused by asthma (2 items) and mother's humor (1 item).

The instruments employed, the psychometric properties of which have been previously studied, are the following:

- The Portuguese version of the School-age Temperament Inventory [SATI] (Lima, Lemos \& Guerra, 2002a) is a self-administered questionnaire for parents of children between 8 and 11 years of age. The inventory allows assessment of four dimensions of the temperament: negative reactivity, task persistence, sociability ${ }^{1}$ (approach/ withdrawal), and (activity). The Cronbach alpha coefficients for the four subscales are $.87, .84, .82$, and .77 , respectively.

- Global Self-Esteem Evaluation Subscale is part of an instrument created by Harter-The Self-perception

\footnotetext{
1 Since this subscale is inversely quoted, in fact, the value expresses the degree of withdrawal of the child.
} 
Profile for Children (1985)] is part of The Selfperception Profile for Children (Harter, 1985) and seeks to evaluate the general feeling that the child has about himself/herself and his/her life experience. Adaptation for the Portuguese population was conducted by Isabel Sá (1997 cited in Ferreira, 2000) and the values of the validity construct proved satisfactory.

- The Portuguese version of the Schoolagers Coping Strategies Inventory (SCSI) (Lima, Lemos and Guerra, 2002b) is a self-administered instrument for children 8 to 12 years old, which assesses the perception of their use of coping strategies during a stressful event personally defined by the child (Ryan-Wenger, 1990). It has a factorial structure of 3 dimensions corresponding to three types of strategies: cognitive behavioral distraction, acting out, and active strategies. The Cronbach alphas range between .72 and .78 , except in the dimension related to active strategies $(\alpha=.50 / .53$ for the frequency and efficacy scales, respectively).

- Scale for Evaluation of Anxiety/Depression in Children - Set of 14 items included in the Child Behavior Checklist (CBCL) by Achenbach (1991) containing descriptions of depressive or anxious behaviors in children. The internal consistency of scale items is good $(\alpha=.78)$, confirming the accuracy of the scale.

- The Portuguese version of the Gresham and Elliot's Social Skills Assessment Scale (1990), from Lemos and Meneses (2002) - is part of Gresham and Elliot's Social Skills Rating System (1990), which is intended to be completed by the child's teacher. The alpha values from the subscales are $\alpha=.93$ for the full range of social skills; $\alpha=.90$ for the self-control subscale; for the cooperation subscale, $\alpha=.91$; and the assertiveness subscale, $\alpha=.93$.

- The Portuguese Version of the Pediatric Quality of Life Inventory 4.0 - PedsQL Lima, Guerra and Lemos (2009) is a modular form for evaluating quality of life in relation to health. For this study, we used a generic self-recording scale for children between 8 and 12 years of age. The internal consistency of the general scale is quite satisfactory $(\alpha=.85)$, confirming the precision of the scale. The coefficients obtained for the physical $(\alpha=.74)$ and psychosocial subscales $(\alpha=.81)$ are also high. The alpha values obtained for the four dimensions assessed by the scale (physical, emotional, educational and social) vary between .67 and .74 .

\section{Design and Procedure}

The design for this study was cross-sectional. The methodology used for the study of relations between the variables involved in the process of adaptation to asthma, was correlational, with multiple linear regression analyses also having been conducted.

After approval from the Hospital's Ethics Committee and the Health Center's Directors, it was the medical assistants (allergists or family physicians) who made first contact with the children and parents (in most cases the mothers), and requested their participation on a voluntary basis. Application of the instruments was conducted during an interview conducted simultaneously with the child and parent, which began with a brief presentation on the study, including reference to the objectives and methodologies. This was followed by a request for the caregiver to fill out the informed consent form (in writing).

At the end of the interview, permission was requested to send the questionnaires to the schoolteachers or administrators, which was again preceded by an explanation of the purpose of these instruments. It should be noted that only 64 teachers for the 89 children surveyed returned the completed form, so that not all subjects from our sample were described and assessed in relation to all the indicators of their school adjustment.

\section{Results}

\section{Psychological adaptation and temperament, coping, self-esteem and stress}

The purpose of the correlational analyses, the values for which appear in Table 1, is to explore the existence of relationships between indicators of psychological adjustment to asthma and the variables related to the child, such as, temperament, frequency and effectiveness of coping strategies, self-esteem and quantity of stressful situations experienced.

We found that only some of the child's characteristics were significantly correlated with all of the adaptation indicators. In regard to temperament, with the exception of the activity dimension, which was not associated with any adaptation indicator, all other dimensions are associated with indicators of adjustment. Negative reactivity, as well as sociability ${ }^{2}$ are positively associated with the indicator of anxiety/depression and negatively with some indicators of overall quality of life and social skills. The task persistence dimension of temperament also shows an association with all indicators in the opposite direction, i.e.

2 Please note that the sociability scale is listed in reverse, so it actually measures the degree of withdrawal. 
THE PSYCHOLOGICAL ADJUSTMENT OF CHILDREN WITH ASTHMA

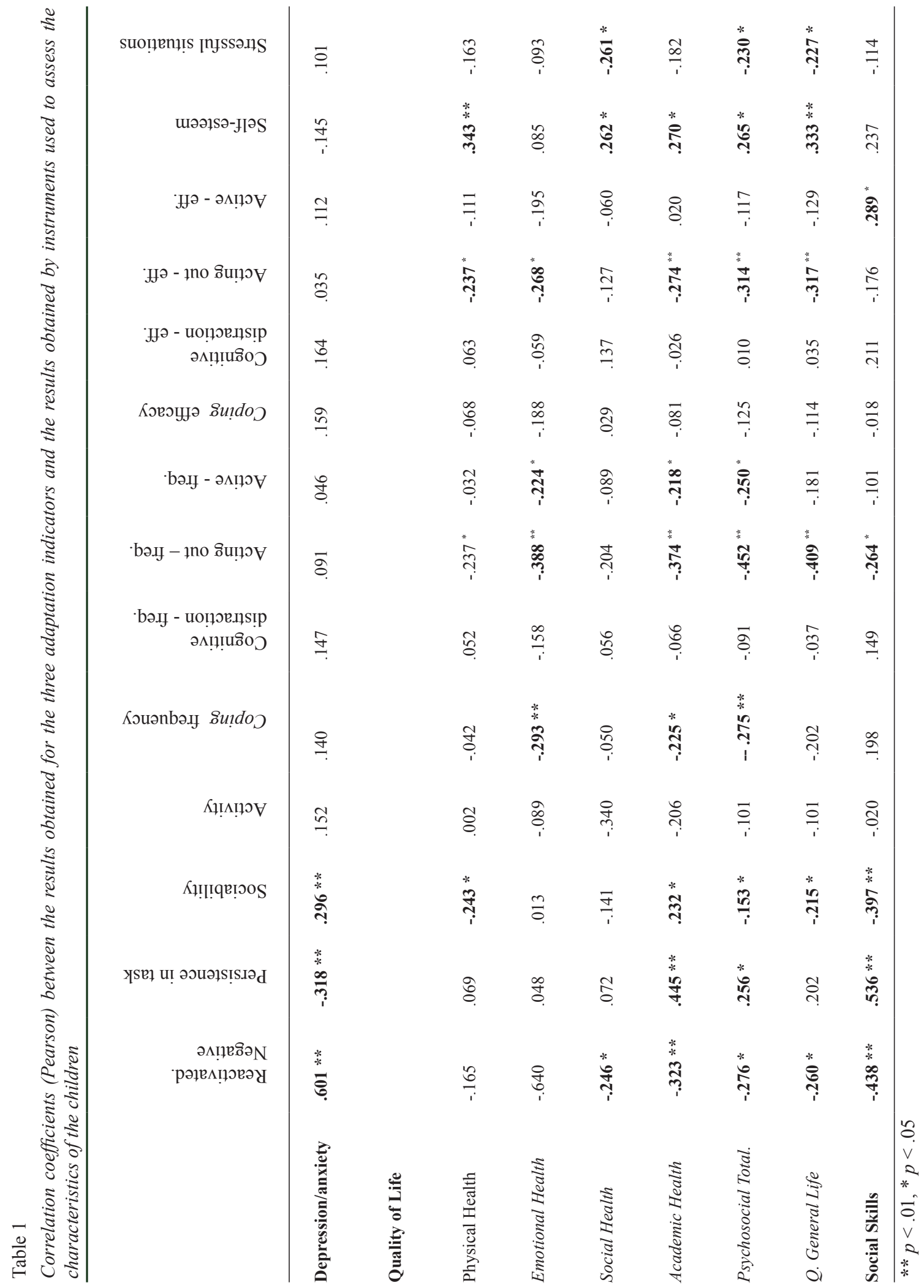


a negative correlation to the depression/anxiety indicator, and positive correlations with the school health dimension of quality of life, as a psychosocial subscale of quality of life and an indicator of social skills.

For coping, we observed a significant negative association between the variables related to acting out strategies (frequency and efficacy) and quality of life and social skills indicators. The variables related to active strategies were significantly associated with some indicators, specifically the frequency of active strategies was associated negatively with the emotional and social dimensions of quality of life, and the perceived efficacy of coping strategies was positively associated with social skills. Self-esteem was only associated with quality of life, and relatively thereto, to all of its dimensions and subscales with the exception of emotional health. Finally, the number of stressful situations correlated negatively with the social dimension, psychosocial subscale and overall quality of life.

\section{Psychological adaptation and characteristics of the child's family}

No association was found between the results obtained in the depression/anxiety indicators, generic quality of life and social skills, and type of household. It was also established that there is no relationship between the humor of the mother and the results for anxiety/depression and social skills, with a statistically significant negative association between the mother's humor and the emotional quality of life $(r=-.222 ; p<.05)$.

Table 2

Correlation coefficients (Spearman's rho) between the results obtained in the three "indicators of adaptation" and the severity of asthma

\begin{tabular}{lc}
\hline & Degree of asthma severity \\
\hline Depression / anxiety & $.210 *$ \\
Quality of Life & \\
Physical Health & $-.270 *$ \\
Emotional Health & $-.291 * *$ \\
Social Health & -.095 \\
School Health & $-.263 *$ \\
Psychosocial Total & $-.355 * *$ \\
General Quality of Life & $-.362 * *$ \\
Social Skills & .17 \\
\hline$* * *$ &
\end{tabular}

$* * * p<.001, * * p<.01, * p<.05$

\section{Psychological adaptation and severity of asthma}

Table 2 shows the correlation (Spearman rho coefficient) between the asthma severity value and the results of the indicators for anxiety/depression, general quality of life and social skills.

As shown in Table 2, the degree of severity of asthma was found to be positively related to two indicators of child adjustment, specifically anxiety and depression and negatively related with the indicator of general quality of life as well as all its dimensions, with the exception of social health.

\section{Variables predictive of psychological adjustment in children with asthma}

In order to investigate which variables are predictive of psychological adjustment in children with asthma, three multiple linear regression analyses were conducted using the method Enter. A preliminary analysis was conducted of the data to detect the presence of multicolinearity ${ }^{3}$ that could prevent the use of multiple regression techniques, which revealed the absence of this phenomenon for each of the independent variables. The value of the square of the coefficient of semi-partial correlation $\left(s r^{2}\right)^{4}$ for each independent variable was also calculated, which allowed us to assess the unique contribution of this variable relative to $R^{2}$ in the set of variables included in the model. The measurements from each of the adaptation dimensions in question in this study were used as criteria variables, i.e., the anxiety/depression index, overall quality of life of the child, and social skills. Variables were introduced which were previously selected according to theoretical criteria, and as a result of the correlational study, as predictive variables. Given the limited number of variables to be included in the model, we decided to calculate a composite index that included two variables; specifically, the stress situations previously experienced by the child in the last year and the number of changes and interference in family life due to the asthma, plus another variable, the type of household (intact or not). This index yielded the sum of the values obtained in each of the variables and was called the stress index, having been coded so that the greater the value the larger the amount of stress experienced by the child and family. The results of multiple regression analysis using the anxiety/depression range results as the dependent variable are found in Table 3.

The regression model found is significant, allowing explanation of $33.9 \%$ of the variance in the anxiety/

3 This concerns the existence of excessively high correlation values between independent variables under study.

$4 \mathrm{The}^{2} \mathrm{r}^{2}$ enables analysis, for each variable, of the percentage of reduction in the amount of R2 (variance explained by the set of independent variables) when this variable is removed from the regression equation. 
Table 3

Regression analysis for prediction of anxiety/depression using the enter method

\begin{tabular}{|c|c|c|c|c|c|}
\hline Independent variables & $\beta$ & $T$ & $s r^{2}$ & $R^{2}\left(R^{2}\right.$ adjusted $)$ & $F(8.77)$ \\
\hline Negative reactivity & .588 & $5.014 * * *$ & .195 & $.401\left(.339^{a}\right)$ & $6.447 * * *$ \\
\hline Sociability & .103 & 1.025 & .008 & & \\
\hline Task Persistence & -.028 & -.271 & .001 & & \\
\hline Global self-esteem & .027 & .285 & .001 & & \\
\hline Stress index & .009 & .095 & .000 & & \\
\hline Coping - frequency & -.182 & -1.228 & .012 & & \\
\hline
\end{tabular}

Note $^{\text {a) }}$ Variance explained by the contribution of individual variables $=24.8$, shared variance $=15.3$

$* * * p<.001$

depression symptoms. The only variable with a significant predictive value is the "negative reactivity" temperament dimension, which, once the variance explained by the remainder is controlled, is responsible for $19.5 \%$ of the variance. A significant solution was also found, explaining $33.7 \%$ of the variance in the results from the social skills scale (Table 4).

The variables that presented a significant predictive value were the "task persistence" temperament dimension and the perceived efficacy of coping strategies. The contribution of task persistence by itself is $11.5 \%$, and that of perceived effectiveness of coping strategies is $4.5 \%$. The overall quality of life is significantly explained by the predictive variables (Table 5). The overall self-esteem was the only variable with a significant predictive value with a unique contribution of $5.2 \%$.

\section{Discussion}

The purpose of this study was to study the variables involved in the adaptation process in children with asthma, especially variables related to factors internal to the child, variables associated with the family, and factors of a more clinical nature.

Relative to the characteristics of the child more associated with psychological adaptation (low anxiety/ depression and high social skills and quality of life), the temperament appears to be particularly significant. In particular, the "negative reactivity" temperament dimension was shown to be associated with weaker adaptation in all three indicators in question. This result is in accordance with the expectations from the theoretical point of view, since, the children who react more negatively from the affective point of view are those who show more symptoms of emotional disturbance, perceiving their quality of life in a less positive manner, and having greater difficulty in social functioning (Wallander \& Varni, 1998). Another dimension of the temperament which we verified to be associated with various adaptation indicators was task persistence, in that the more persistent the child, the fewer the symptoms of anxiety/depression were present, the better was the child's quality of life in school and psychosocial terms, and the better their social functioning. This last association, between task persistence and social skills, confirms the results of previous studies, especially that of Benchell and Glasgow (1997) regarding the role of temperament in adaptation in children with diabetes. Carey (2004) also supports a positive association between adaptation to school and task persistence. The correlational analysis demonstrated that the temperament dimension of sociability was also associated with the three adaptation indicators, which is in conformity with the literature regarding resilience, according to which sociable temperament is a protective factor against risk situations (Kimchi \& Schaffner, 1990 cited in Sharp \& Cowie, 1998). The strongest association was found with social skills, which is understandable given the closeness of the conceptual constructs, or rather from the theoretical point of view it is expected social skills to facilitate the approach to new situations and people unknown to the child, which is one of the indicators in the instrument that evaluates temperament.

In relation to associations with the dimensions of quality of life, the physical health dimension stood out, which could mean that the more the child was withdrawn the more their physical limitations and activities are considered problematic. Sociability also demonstrated a positive association with anxiety/depression, which confirmed our expectations, since it is expected that the more withdrawn a child is, the more they will experience difficulties in maintaining the emotional balance when confronted by the challenges posed by tasks in their development in general and the management of their particular disease.

In regards to coping, the correlational analysis conducted demonstrated that the strategies that were associated significantly with adaptation indicators were acting- out and active strategies. We observed that more frequent employment of acting-out strategies was 
Table 4

Regression analysis for prediction of social skills using the enter method

\begin{tabular}{|c|c|c|c|c|c|}
\hline Independent variables & $\beta$ & $T$ & $s r^{2}$ & $R^{2}\left(R^{2}\right.$ adjusted $)$ & $F(8.51)$ \\
\hline Negative reactivity & -.150 & -1.117 & .014 & $.427\left(.337^{\mathrm{a}}\right)$ & $4.752 * * *$ \\
\hline Sociability & -.160 & -1.270 & .018 & & \\
\hline Task Persistence & .385 & $3.196 * *$ & .115 & & \\
\hline Global self-esteem & .067 & .580 & .004 & & \\
\hline Stress index & .007 & .064 & .000 & & \\
\hline Coping-efficacy & .317 & $2.005 *$ & .045 & & \\
\hline Coping - frequency & -.204 & -1.256 & .0177 & & \\
\hline
\end{tabular}

Note. ${ }^{\text {a) }}$ Variance explained by the contribution of individual variables $=21.5$, shared variance $=21.2$

$* * * p<.001, * * p<.01, * p<.05$

Table 5

Regression analysis to predict the overall quality of life using the enter method

\begin{tabular}{|c|c|c|c|c|c|}
\hline Independent variables & $\beta$ & $T$ & $s r^{2}$ & $R^{2}\left(R^{2}\right.$ adjusted $)$ & $F(8.77)$ \\
\hline Negative reactivity & -.084 & -.632 & .004 & $.23\left(.15^{\mathrm{a}}\right)$ & $2.882 * *$ \\
\hline Sociability & .177 & -1.545 & .024 & & \\
\hline Task Persistence & .084 & .723 & .005 & & \\
\hline Global self-esteem & .242 & $2.269 *$ & .052 & & \\
\hline Stress index & -.176 & -1.732 & .030 & & \\
\hline Coping-efficacy & .030 & .188 & .000 & & \\
\hline Coping - frequency & -.136 & -.809 & .007 & & \\
\hline
\end{tabular}

Note. Variance explained by the individual contribution of the variables $=15$, shared variance $=8$

$* * p<.01, * p<.05$

associated with poorer quality of life (emotional and school dimensions and overall results) and a lower level of social skills. The perceived efficacy of this type of strategy was also related to a lower quality of life. As for active type strategies, more frequent employment thereof was also associated with a lower quality of life, while their perceived efficacy was found to be related to better social skills. These last results merit some examination, in so far as the majority of research associates more frequent use of active strategies with better adaptation. Alternatively, our results seem to suggest that the need to use coping strategies increases as the child identifies the existence of greater crises or challenges. The manner in which items are formulated to evaluate this variable, having two ideas simultaneously which may render response difficult for the child, may also have an influence.

Global self-esteem was another of the child variables that was shown to be positively associated with quality of life, specifically at physical, social, and school levels, which corroborates findings reported by Vinson (2002). The existence of an association between quantity of stressful situations previously experienced by the children over the prior year and their quality of life is consistent with the existing literature. According to Ewanston,
Williams and Nunn (2000 cited in Isaacs \& Sewell, 2003) the occurrence of stressful life events constitutes a risk for the occurrence of psychosocial problems in children with chronic illnesses. Additionally, according to Moran (2000), situations of loss and intense frustration may trigger asthma attacks. Thus, it is to be expected that the quality of life perceived by the child decreases when confronted with an increase and aggravation of asthma symptoms. The type of events most experienced by the children in the sample were change of residence and school, which may cause feelings of insecurity in the child, especially at a social level, in that both situations cause the child to meet new peers. This hypothesis seems plausible to us, with the results found and considering that our correlational analysis gave us an opportunity to verify that the occurrence of stressful situations were found to be negatively associated with the social dimension of quality of life.

Regarding the relationship between family characteristics of children and indicators of adjustment, no significant associations were found except on the humor of the mother, which was associated negatively with the emotional quality of life of the child. This result can be interpreted as reflecting the importance that the mental 
health of the mother (or primary caregiver) plays on the child's emotional balance, which, has been repeatedly demonstrated both in relation to psychological adjustment of any child or relative to adaptation in children with asthma (e.g. Frankel \& Wambolt, 1998; Kaugars, Klinnert \& Bender, 2004). The fact that mothers, themselves, do not possess major internal resources has likely made them less available to children to support their efforts to adapt to asthma, which can negatively affect their emotional wellbeing. The lack of an association between the mother's humor and anxiety/depression, contradicts what would be expected from a theoretical and empirical perspective, especially the position advocated by some authors that a mother's response to items related to symptoms of anxiety/depression is often skewed by her own mood (Bender, Annet, Duttamel, Rand \& Strunk, 2000; Kaugars, Klinnert \& Bender, 2004). This result may be related to the fact that only a small percentage of mothers have reported having a very negative humor. Another possible explanation for this unexpected result may be that this variable was evaluated using only one item. The negative association found between the severity of asthma and the school health dimension of quality of life corroborates the results previously obtained by Bender and colleagues (2000), while the negative correlation with the emotional health dimension contradicts the findings from research conducted by Klinnert, McQuaid, McCormick, Adinoff and Bruant (2000).

The regression analysis conducted on the anxiety/ depression indicator revealed that only a temperamental variable for negative reactivity had a significant predictive value. No other variable included in the model showed a significant individual contribution, although they contribute to the overall explained variance. Overall, the group of variables included in the model explains little more than one third of the variance in the results for the anxiety/depression variable, therefore it would be relevant to study other variables that may provide a more complete vision of adaptation in children with asthma. However, the results merit some reflection on our part, as follows.

The fact that the negative reactivity has presented a significant predictive value, verifying that the higher the values of this dimension of temperament, the higher the anxiety/depression, contradicts the results of other studies (Wertlieb et al., 1987 cited in Rothbart \& Bates, 1998; Varni et al., 1989c cited in Wallander \& Varni, 1998). According to Rothbart and Bates (1998) it is likely that a child with high negative reactivity will react more intensely to stressful events, increasing the risk of developing symptoms of anxiety/depression.

According to Schuman and LaGreca (1999), social adjustment represents an area of particular vulnerability for children with chronic illness. As such, we also conducted a regression study to predict the social skills of children in the sample, and found that only two of the variables included in the model significantly predicted this adaptation indicator, which were task persistence and the efficacy of coping. Of these, the one with greater explanatory power was task persistence. The model developed explains a little more than a third of the variance of the results for the social skills indicator. For task persistence, the data revealed that the higher this value was for the children evaluated, the higher their score in terms of social skills. The relationship between these variables, as we mentioned in connection with the correlational analysis, makes sense from a theoretical viewpoint, and has been demonstrated in research (Martin, Olejnik \& Gaddis, 1994; Rothbart \& Jones, 1998 cited in McClowry, 2002), particularly in the area of study of chronic disease in childhood (Benchell \& Glasgow, 1997).

The variable related to the efficacy of coping strategies also showed a significant effect, verifying that the children who perceived their coping strategies as most effective were those who had more social skills, given that this is consistent with the results obtained in the correlation study on the strategies of such asset. From a theoretical point of view, it is expected that the child's perception of the efficacy of their coping strategies would be a more reliable reflection of the success of their confrontation strategies, and, as such, more determinant of adaptation. In other words, the fact that the child was already able to learn how to choose a repertoire of effective strategies to deal with their problems will have a positive impact on their adaptation: in this case, in terms of social functioning in the school context. This interpretation is consistent with the position of some authors who argue that the experience of chronic illness can bring moments of growth, because in this manner children experience more opportunities for the development of effective confrontation strategies, which will make them more competent, including in terms of dealing with other forms of adversity and stress (Sharp \& Cowie, 1998).

To predict the perceived quality of life for the child, we also conducted a regression study using the same criterion variables that were studied in the models for anxiety/ depression and social skills. The only one that appeared as predictive was global self-esteem, although the other variables contributed to the total explained variance. Similarly, Vinson (2002) found that the greater the selfesteem of a child with asthma, the higher was their quality of life for emotional dimensions and limitation of activities. The relationship between self-esteem and quality of life is intuitive, in that the general feeling about the value itself is almost a prerequisite for well-being.

A result that merits mention is the existence of a significant proportion of shared variance, since it reinforces the idea of multi-determination and the interaction between the variables influencing adaptation. According to the developmental psychopathology perspective, individual trajectories are multishaped and depend on 
complex relationships between various factors (Cichetti $\&$ Toth, 1998). Thus, in addition to the variables that are independently significant predictors of adaptation, one must not forget that the whole set of other variables (e.g., the humor of the mother or the level of stress experienced by the child) should be considered in the child's adaptation efforts. At the same time, the amount of variance that was explained by the model developed suggests that other factors driving the adaptation of children with asthma be looked at, such as biological, social or family factors. Among the biological and/or biomedical factors, in addition to severity of the disease, other key aspects of the course of the disease could be studied, such as the type of medication used to control symptoms, the degree of adherence to treatment, the existence of complications associated with asthma that may interfere in the management of the disease, such as sinusitis or bronchitis, among others. Research has demonstrated that other types of factors that could have been introduced in the prediction model in addition to those studied, such as variables related to the family's environment, are determining factors in the adaptation of children with asthma. For example: parent-child interaction (Bleil, Ramesh, Miller \& Wood, 2000), parenting/educational practices (Kaugars, Klinnert \& Bender, 2004), the quality of family relationships (Edwards \& Davis, 1997) and social support within the family (Edwards \& Davis, 1997, Kaugars, Klinnert \& Bender, 2004).

We believe that this discussion would not be complete without making reference to some limitations of this study, including: (a) the small sample size, which in some tests was even further decreased due to non-compliance on the part of teachers in completing two assessment instruments (b) the selection process for the sample, which, not being random, compromised the generality of the results.

In short, we believe that this research contributes to understanding the psychological processes that operate in the psychological adjustment of children with asthma, as well as in relation to adaptation to other types of chronic disease in childhood. Above all, this study offers important clues for research and intervention in child health, and, it would be interesting to conduct further longitudinal studies in the future in order to confirm the direction of causal relationships between variables, suggested by this research.

\section{References}

Achenbach, T.M. (1991). Manual for the Child Behavior Checklist and Revised Child Behavior Profile. Burlington: University of Vermont, Department of Psychiatry.

Bacharier, L.B., Boner, a., Carlsen, K-H., Eigenmann, P.A., Frischer, T., Gotz; M. et al. (2008) Diagnosis and treatment of asthma in childhood: a PRACTALL consensus report. Allergy. 63, 5-34.
Barros, L. (1999). Psicologia Pediátrica: Perspectiva desenvolvimentista. Lisboa: CLIMEPSI.

Benchell, J., \& Glasgow, A. (1997). The Role of Temperament in Children with Insulin-Dependent Diabetes Mellitus. Journal of Pediatric Psychology, 22(6), 795-809.

Bender, B.G., Annet, R.D., Duttamel, T.R., Rand, C., \& Strunk, R.C. (2000). Relationship between disease and psychological adaptation in children in the Childhood Asthma Management program and their Families. Archives Pediatric Adolescence Medicine, 154(7), 706-713.

Bleil, M.E., Ramesh, S., Miller, B. D., \& Wood, B.L. (2000). The influence of Parent-Child Relatedness on Depressive Symptons in Children with Asthma: Tests of Moderator and Mediator Models. Journal of Pediatric Psychology, 25(7), 481-491.

Brown, R.T., Wiener, L.W., Kupst, M, J.K., Brennan, T., Behrman, R., Compas, B.E. et al. (2008). Single Parenting and Children with Chronic Illness: An Understudied Phenomenon. Journal of Pediatric Psychology, 33(4), 408-421.

Carey, W. (2004). Temperament and the Pediatrician. Reprinted from Pediatric Development and Behaviour Online. Consultado a 19 de Julho de 2004 em http.//Www.dppeds. org/articles/detail_p.cfm? id=18.

Carranza, J.A, \& Salinas, C. G. (2003). Temperamento en la infancia: aspectos conceptuales básicos. Barcelona: Ariel Psicología.

Cichetti, D., \& Toth, S. (1998). Perspectives on Research and Practice in Developmental Psychology. In William Damon (Editor in Chief), I. Siegel, A. Renninger. Child Psychology. Volume Four: Child Psychology in Practice. (pp.479-559). New York: Wiley.

Creer, T.L., \& Bender, B.G. (1995). Pediatric Asthma. In M. Roberts (Eds), Handbook of Pediatric Psychology (pp 219240). London: Guilford Press.

Edwards, M., \& Davis, H. (1997). Counselling Children with Chronic Medical Conditions. Leicester: British Psychological Society.

Ferreira, H. I. M. M. (2000). A competência social no contexto escolar: um estudo na interface entre a competência social e a realização académica na criança. Dissertação de Mestrado apresentada à Faculdade de Psicologia e Ciências da Educação da Universidade do Porto.

Frankel, K., \& Wamboldt, M. (1998). Chronic Childhood Illness and Maternal Mental Health - Why Should We Care? Journal of Asthma, 35(8), 621-630.

Global Initiative for Asthma- GINA (1995). Global strategy for asthma management and prevention. NHLBI/WHO workshop report. National Institutes of Health, National Heart, Lung and Blood Institute, NIH publication number 95-3659.

Gresham, F. M. \& Elliot, S. N. (1990). Social Skills Rating system: Manual. Circle Pines, MN: American Guidance Service.

Harter, S. (1985). Adolescent Self-Perception Profile. Nonpublished manuscript.

Hérnandez, M. J. (1995). Aspectos básicos da Psicopatologia Infantil. In M.J. Hernádez (Ed). Psicopatologia Infantil. (pp.19-35). Granada: Ediciones Aljibe. 
Isaacs, D. \& Sewell, J.R. (2003). Children with chronic conditions. Medical Journal of Australia, 179(5),235-236.

Kaugars, A.S., Klinnert, M.D., \& Bender, B.G. (2004). Family Influences on Pediatric Asthma. Journal of Pediatric Psychology, 29(7), 475-491.

Klinnert, M., McQuaid, E., McCormick, D., Adinoff, A., \& Bruant, N. (2000). A Multimethod Assessement of Behavioral and Emotional Adjustment in Children with Asthma. Journal of Pediatric Psychology, 25(1), 35-47.

Lemos, M. S. \& Meneses, H. I. (2002). A avaliação da competência social: Versão Portuguesa da Forma para professores do SSRS. Psicologia, Teoria e Pesquisa, 18(3),167-274.

Lima, L., Guerra, P.M. \& Lemos, M.S. (2009). Adaptação da escala genérica do Inventário Pediátrico de Qualidade de vida - Pediatric Quality of Life Inventory 4.0 - PedsQL, a uma população portuguesa. Revista Portuguesa de Saúde Pública, 8, 83-95.

Lima, L., Lemos, M., S. \& Guerra, M.P. (2002a). Examination of the validity and reliability of the Portuguese version of the school-age temperament inventory (SATI) by McClowry, 1995. Poster presented at the 16th Conference of the European Health Psychology Society (2-6 October).

Lima, L., Lemos, M. S. \& Guerra (2002b). Estudo das qualidades psicométricas do SCSI (Schoolagers' Coping Strategies Inventory) numa população portuguesa. Análise psicológica, 4(20), 555-570.

Martin, R.P., Olejnik, S. \& Gaddis, L. (1994). Is temperament an important contributor to schooling outcomes in elementary school? Modeling effects of temperament and scholastic ability on academic achievement. In W.B. Carey \& S.C. McDevitt (Eds). Prevention and early intervention: Individual Differences as risk factorsfoor the mental health of children.(pp59-68). New York: Bruner/Mazel.

Masten, A.S., Morison, P., Pellegrini, D. \& Tellegen, A. (1992). Competence under stress: risk and protective factors. In J. Rolf, A. Masten, D. Ciccheti, K, Nuechterlein \& S. Weintraub,. (Eds) Risk and Protective Factors in the Development of Psychopathology (pp.236-256). Cambridge: Cambridge University Press.

McClowry, S.G. (1995). The Development of the School-age Temperament Inventory. Merril Palmer Quartely.41(3), 271285.

McClowry, S.G. (2002). The temperament Profiles of School Age Children. Journal of Pediatric Nursing, 17(1),3-10.

McQuaid, E.L., Kopel, S.J., \& Nassau, J.H. (2001). Behavioral Adjustment in children with asthma : A meta-analysis. Journal of Developmental and Behavioral Pediatrics; 22(6), 430-439.

McQuaid, E. \& Walders, N. (2003). Pediatric Asthma. In M. Roberts (Eds), Handbook of Pediatric Psychology (pp 269285). London: Guilford Press.

Mishoe, S., Baker, R., Poole, S., Harrel, L., Arant, C., \& Rupp, N. (1998). Development of an Instrument to Assess Stress Levels and Quality of Life in children with Asthma. Journal of Asthma, 35(7), 553-563.
Moran, M. G. (2000) Doenças Pulmonares e Reumatológicas. In A. Stoudemire (org). Fatores Psicológicos Afetando Condições Médicas. (pp. 143-158). Porto Alegre: Artes Médicas Sul.

Pauli-Pott, U., Darui, A., \& Beckman, D. (1999). Infants with Atopic Dermatitis: Maternal Hopelessness, Child-Rearing Attitudes and Perceived Infant Temperament. Psychotherapy and Psychosomatics, 68, 39-45.

Rothbart, M., \& Bates, J. (1998). Temperament. In W. Damon \& N. Eisenberg (Eds), Handbook of child psychology-Volume 3: Social, emotional and Personality development (pp.105164). New York: Jonh Willey \& Sons.

Ryan-Wenger, N.(1990). Development and psychometric properties of the schoolagers' coping strategies inventory. Nursing Research, 39(6), 344-349.

Ryan-Wenger, N. (1996). Children, coping and the stress of Illness: a synthesis of the research. Journal of The Society of Pediatric Nurses, 1(3) 126-139.

Ryan-Wenger, N., Sharrer, V., \& Wynd, C. (2000). Stress, Coping and Health In Children. In V.H.Rice (Ed). Handbook of Stress, Coping and Health. (pp.265-293). Thousand Oaks: Sage.

Schuman, W., \& La Greca, A. (1999). Social Correlates of Chronic Disease. In R. T. Brown (Eds.), Cognitive Aspects of Chronic Illness in Children. (pp. 289-311). London: Guilford Press.

Sharp, S., \& Cowie, H. (1998). Counselling and Supporting Children in Distress. London: Sage.

Spirito, A., Stark, L.J., Gil, K.M., \& Tyc, V.L. (1995). Coping with everyday and disease-related by chronically ill children and adolescents. Journal of The American Academy of Child and Adolescent Psychiatry, 34(3), 283-291.

Thompson, R.J., \& Gustafson, K. E. (1996). Adaptation to Chronic Childhood Illness. Washington: American Psychological Association.

Thompson, R. J., Gustafson, K. E., George, L. K., \& Spock, A.. (1994). Change Over a 12-Month Period in the Psychological Adjustment of Children with Cystic Fibrosis. Journal of Pediatric Psychology, 19(2), 189-203.

Varni, J.W., Seid, M., \& Kurtin, P.S. (2001) The PedsQL 4.0: Reliability and validity of the Pediatric Quality of Life Inventory 4.0 version, Medical Care, 39, 800-812.

Vinson, J.A. (2002). Children With Asthma : Initial Development of The Child Resilience Model. Pediatric Nursing, 28(2), 149-158.

Wallander, J., \& Varni, J. (1998). Effects of Pediatric Physical Disorders on Child and Family Adjustment. Journal Child Psychology Psychiatry, 39(1), 29-46.

World Health Organization (2000). Bronchial Asthma. WHO Fact Sheet $n^{\circ} 206$. Revised January 2000.

Received November 13, 2008 Revision received March 31, 2009 Accepted May 23, 2009 